troubleshooting guide that includes web pages, help and other extras, and a linked website with more resources. McKellar also offers alternative strategies for multiple learning styles. Although this book can't replace a great teacher, it certainly helps support school instruction.

Math Doesn't Suck connects the ideas taught in the classroom to a young teen's daily life. My favourite example is how to find the 'Greatest Crush Factor', or GCF. She compares the factors that made her like her old "crush" with what makes her like her new crush. She lists the factors, circling what they have in common, identifying the greatest thing they have in common - et voilà, GCF.

Is it sexist to do whatever it takes to make sure that a girl likes maths early on in her education in order to pursue it as a career, or even to simply like it recreationally? I don't think so. Positive female role models such as McKellar - who embrace mathematics as a part of everyday life, and are still funny and cool - let a key audience know that it's okay to be great at mathematics.

Today's teenage girl may have no idea who Winnie Cooper is, but Winnie knows her! Joanna S. Sabatino-Hernandez is an algebra and geometry teacher at Cabin John Middle School, 10701 Gainsborough Road, Potomac, Maryland 20854, USA.
Math Doesn't Suck
by Danica McKellar
Hudson Street Press: $\$ 23.95$

\title{
The scene is set
}

\section{Glenn Murphy}

With the growth of the popular-science genre, science-related books for children have become more numerous and varied than ever before. Yet most kids would happily choose TV or MySpace over the average non-fiction text. So pitching the tone and content correctly is paramount. Authors have to do more than avoid the obvious pitfalls of technical language. They have to provide a solid context for every bit of content. If it isn't relevant to children or they can't recognize the familiar, why should they care?

Phillip Ardagh always succeeds at putting science and technology in context for children. His books are fun, engaging, larger than life and spilling over with interesting facts and anecdotes on every subject. Wow! Inventions That Changed the World (10-16 years) covers major breakthroughs in the history of science and technology.

Ardagh sticks to machines and vehicles rather than concepts or processes. Each chapter begins with a scene from an invention's history, such as the first phone call in Bell's laboratory: "Acid from the battery spills on to his trousers and Bell leaps to his feet. 'Mr Watson! Come here! I want you!' he cries ... he has just made the world's very first telephone call." Ardagh then launches into the background and historical setting. From wheels to cars, mining carts to steam trains, he bobs lightly along, adding facts, figures and anecdotes along the way. The main

Wow! Inventions That Changed the World by Phillip Ardagh

Macmillan: $€ 3.99$

Natural History Museum Animal Records

by Mark Carwardine

Natural History Museum: $£ 20$

Actual Size

by Steve Jenkins

Francis Lincoln: $£ 9.99$

How To Be A Brain Surgeon

by Amanda Li

Macmillan: $£ 3.99$ themes - technology in our everyday lives and appreciating inventions in contrast to what went before - come through loud and clear. And like all the best educational texts, young readers remain unaware of how much they're really learning.

Books on animals have a head start with children. Natural History Museum Animal Records (6-14 years) (pictured) by Mark Carwardine is a compendium of animal facts (biggest, smallest, fastest, laziest, most dangerous, and so on). scale across a double-page spread. These pictures are worth the proverbial 1,000 words of description. Accompanied by facts, statistics and dimensions - "A 60-centimetre-long tongue! This must be a giant anteater snacking on its favourite food, termites." - the illustrations are rounded off with a few pages of text about each animal. The idea is quite simple; the effect is wonderful.

Another way of contextualizing science is to relate it to the question ' what do you want to be when you grow up?'. How To Be (r) A Brain Surgeon (8-12 years) by Amanda Li is part of a new series of books that does exactly this. You can just imagine a pushy parent buying it for their child in the hope of creating an aspiring 12-year-old neurosurgeon. Happily, the remit is wider than the title implies - exploring the history of medical science, technology and practice more generally before focusing on the brain and neurosurgery. The tone drifts into the formal, passive voice of the academic curator at times, but generally clips along well. The book offers some genuine Most chapters are divided into linnaean orders. The bird chapter, in contrast, is sectioned into physiological and behavioural categories (such as talking birds, birds in flight). This neatly emphasizes the diversity of what to most children is a physically homogeneous group.

The book frames many 'record-breaking' animal characteristics as evolutionary adaptations, and features regular nods towards the relevance and importance of biodiversity and conservation. Like the arrangement, the tone is somewhat encyclopaedic, with a fair amount of jargon - making me wonder at times if this inspiring visual reference book is actually aimed at kids or at a more general family audience. Nonetheless, I would have loved a book like this as a child.

Conversely, Actual Size (4-8 years) by Steve Jenkins keeps it simple for younger readers, and features a collection of artistic collages of animals or parts of animals. Each is printed to insights and background for kids where oth erwise there is none, and it avoids being too preachy or sugar-coating the themes.

These books vary in approach, tone and tar get age range. In providing children with a con text for science and technology in their lives, all of them have something to offer younger readers. The central importance of context is easily forgotten in the race to produce 'educational' books aimed at improving the 'scientific literacy' of children and young adults. Education begins with engaging interest. Without that, most attempts at imparting information - whether formal or informal - will either fail or be actively counterproductive. So if you're buying science-related books to encourage your offspring, choose carefully. The wrong books will put them off science completely. The right ones can inspire them for life. Glenn Murphy is a US science writer and is the author of Why Is Snot Green? 